\title{
All grades of severity of postoperative adverse events are associated with prolonged length of stay after lung cancer resection
}

\author{
Zach Zhang, ${ }^{a}$ Fargol Mostofian, BHSc, ${ }^{a}$ Jelena Ivanovic, MSc, PhD,${ }^{\mathrm{b}, \mathrm{c}}$ Sebastien Gilbert, MD, FRCSC,,${ }^{\mathrm{a}, \mathrm{d}}$ \\ Donna E. Maziak, MDCM, MSc, FRCSC, FACS, ${ }^{\text {a,b,c,d }}$ Farid M. Shamji, MD, FRCSC, , , \\ Sudhir Sundaresan, MD, FRCSC, FACS, ${ }^{\mathrm{a}, \mathrm{c}, \mathrm{d}}$ Patrick J. Villeneuve, MDCM, PhD, FRCSC, ${ }^{\mathrm{a}, \mathrm{d}}$ and \\ Andrew J. E. Seely, MD, PhD, FRCSC ${ }^{a, b, c, d}$
}

\section{ABSTRACT}

Objective: To determine whether all grades of severity of postoperative adverse events are associated with prolonged length of stay in patients undergoing pulmonary cancer resection.

Methods: This was a retrospective cohort study of all patients who underwent pulmonary resection with curative intent for malignancy at The Ottawa Hospital, Division of Thoracic Surgery (January 2008 to July 2015). Postoperative adverse events were collected prospectively with the Thoracic Morbidity \& Mortality System, based on the Clavien-Dindo severity classification. Patient demographics, comorbidities, preoperative investigations, cardiopulmonary assessment, pathologic staging, operative characteristics, and length of stay were retrospectively reviewed. Prolonged hospital stay was defined as $>75$ th percentile for each procedure performed (wedge resection 6 days, segmentectomy 6 days, lobectomy 7 days, extended lobectomy 8 days, pneumonectomy 10 days). Univariable and multivariable logistic regression analyses were conducted to identify factors associated with prolonged hospital stay.

Results: Of 1041 patients, $579(55.6 \%)$ were female, $610(58.1 \%)$ were $>65$ years old, $232(22.3 \%)$ experienced prolonged hospital stay, and 416 (40.0\%) patients had $\geq 1$ postoperative adverse event. Multivariable analyses identified significant $(P<.05)$ factors associated with prolonged hospital stay to be (odds ratio; $95 \%$ confidence interval): lower diffusion capacity of the lung for carbon monoxide $(0.99 ; 0.98-0.99)$, surgical approach: open thoracotomy $(1.8 ; 1.3-2.5)$, and presence of any postoperative adverse event: Grade I (5.8; 3.3-10.2), Grade II (6.0; 4.0-8.9), Grade III (11.4; 7.0-18.7), and Grade IV (19.40; 7.1-55.18).

Conclusions: Lower diffusion capacity of the lung for carbon monoxide, open thoracotomy approach, and the development of any postoperative adverse event, including minor events that required no additional therapy, were factors associated with prolonged hospital stay. (J Thorac Cardiovasc Surg 2018;155:798-807)

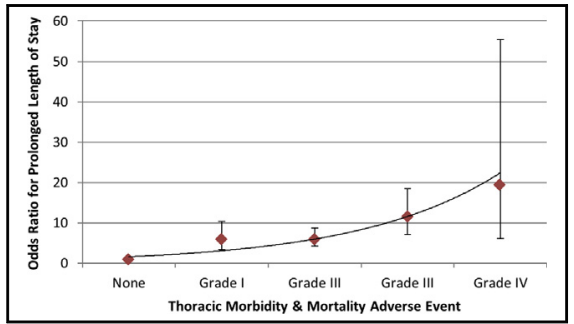

Association between Thoracic Morbidity \& Mortality adverse event grade and odds ratio for prolonged length of stay.

\section{Central Message}

All adverse events, including minor ones, are associated with prolonged hospital stay after lung cancer resection.

\section{Perspective}

Along with lower diffusion capacity of the lung for carbon monoxide and open thoracotomy, multivariable analyses of 1041 cases at a single institution found that the occurrence of any postoperative adverse event, including minor events that require no treatment (Grade I) or pharmacological therapy only (Grade II), significantly increased the odds of having prolonged length of stay in patients undergoing pulmonary resection for lung cancer.

See Editorial Commentary page 808 .
Pulmonary resection for lung cancer carries significant risks of postoperative adverse events (AEs) and prolonged length of stay (PLOS). Patients with cancer who have undergone

\footnotetext{
From the ${ }^{\mathrm{a} F a c u l t y}$ of Medicine, and ${ }^{\mathrm{b}} \mathrm{S}$ chool of Epidemiology, Public Health, and Preventative Medicine, University of Ottawa; ${ }^{\mathrm{c}}$ Clinical Epidemiology Program, Ottawa Hospital Research Institute; and ${ }^{\mathrm{d}}$ Division of Thoracic Surgery, The Ottawa Hospital, Ottawa, Ontario, Canada.

Funding was received from the University of Ottawa 2015/2016 Undergraduate Research Opportunity Program (UROP) Award to support the efforts of Zach Zhang, MD Candidate.

Presented at the Canadian Surgery Forum/Canadian Association of Thoracic Surgeons (CSF/CATS), Toronto, Canada, September 8-10, 2016.
}

lobectomy and have a PLOS were found to have greater rates of postoperative AEs and mortality and lower 5-year survival rates. ${ }^{1,2}$ In addition, PLOS leads to greater costs

\footnotetext{
Received for publication Feb 22, 2017; revisions received Aug 28, 2017; accepted for publication Sept 16, 2017; available ahead of print Nov 2, 2017.

Address for reprints: Andrew J. E. Seely, MD, PhD, FRCSC, Division of Thoracic Surgery, The Ottawa Hospital-General Campus, 510 Smyth Rd, Ottawa, Ontario, K1H 8L6, Canada (E-mail: aseely@toh.ca). $0022-5223 / \$ 36.00$

Copyright $(\subset) 2017$ by The American Association for Thoracic Surgery https://doi.org/10.1016/j.jtcvs.2017.09.094
} 


\section{Abbreviations and Acronyms \\ $\mathrm{AE}=$ adverse event \\ $\mathrm{CI}=$ confidence interval \\ COPD = chronic obstructive pulmonary disease \\ DLCO = diffusion capacity of the lung for carbon monoxide \\ ERAS = enhanced recovery after surgery \\ $\% \mathrm{FEV}_{1}=$ forced expiratory volume for 1 second expressed as a percentage of the forced vital capacity \\ IQR = interquartile range \\ LOS = length of stay \\ OR = odds ratio \\ PFT = pulmonary function test \\ PLOS = prolonged length of stay \\ TM\&M $=$ Thoracic Morbidity \& Mortality \\ VATS = video-assisted thoracoscopic surgery}

Scanning this QR code will take you to a supplemental video for the article.

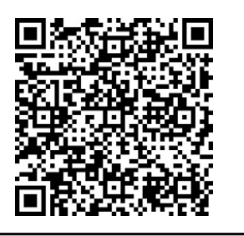

for hospital per patient. ${ }^{3}$ Given the important impact of PLOS on hospital costs, determining predisposing factors associated with PLOS can be used to improve quality of care for patients undergoing pulmonary resection. Several previous studies have identified risk factors for PLOS to be older age, male sex, comorbid illnesses, cardiopulmonary status, and postoperative complications. ${ }^{1-6}$ However, most studies do not include minor AEs in their analyses or thoracic surgery-specific AEs. The impact of minor AEs on thoracic surgery length of stay (LOS) remains unknown.

The Thoracic Morbidity \& Mortality (TM\&M) classification system has been used to report and monitor the incidence of thoracic surgery-specific AEs classified by grades according to the degree of treatment required to manage the AEs. ${ }^{7}$ The TM\&M system is reliable and reproducible, ${ }^{8}$ has been implemented by several groups internationally, ${ }^{9,10}$ and provides a simple and objective method to classify severity of AEs. ${ }^{1-13}$

The objective of this study was to identify perioperative factors associated with increased odds of PLOS after pulmonary resection with curative intent. We used the TM\&M classification system, including all grades of AEs independently, to determine their individual effect on PLOS.

\section{PATIENTS AND METHODS}

\section{Study Design, Setting, and Population}

This was a retrospective cohort study. All consecutive patients who underwent pulmonary resection with curative intent for malignant disease at
TABLE 1. Patient demographics, medical history, preoperative evaluation, staging, procedure performed, and approach

\begin{tabular}{|c|c|c|c|}
\hline & $\begin{array}{c}\text { Expected } \\
\text { LOS, } \mathbf{n}=\mathbf{8 0 9}\end{array}$ & $\begin{array}{l}\text { PLOS, } \\
\mathrm{n}=\mathbf{2 3 2}\end{array}$ & $P$ value \\
\hline \multicolumn{4}{|l|}{ Patient characteristics } \\
\hline \multicolumn{4}{|l|}{ Sex } \\
\hline M & $343(42.4 \%)$ & $119(51.3 \%)$ & .016 \\
\hline $\mathrm{F}$ & $466(57.6 \%)$ & $113(48.7 \%)$ & \\
\hline Age & $809(77.7 \%)$ & $232(22.3 \%)$ & .089 \\
\hline \multicolumn{4}{|l|}{ Medical history } \\
\hline \multicolumn{4}{|l|}{ Comorbidities } \\
\hline Diabetes & $137(16.9 \%)$ & $39(16.8 \%)$ & .965 \\
\hline Coronary artery disease & $123(15.2 \%)$ & $48(20.6 \%)$ & .047 \\
\hline Peripheral vascular disease & $49(5.9 \%)$ & $17(7.3 \%)$ & .484 \\
\hline Cerebrovascular history & $33(4.1 \%)$ & $10(4.3 \%)$ & .876 \\
\hline Hypercholesterolemia & $161(19.9 \%)$ & $49(21.1 \%)$ & .683 \\
\hline Hypertension & $373(46.1 \%)$ & $105(45.3 \%)$ & .819 \\
\hline Pulmonary hypertension & $0(0 \%)$ & $2(0.9 \%)$ & .008 \\
\hline Congestive heart failure & $0(0 \%)$ & $2(0.9 \%)$ & .008 \\
\hline Renal failure & $12(1.5 \%)$ & $1(0.4 \%)$ & .203 \\
\hline COPD & $173(21.4 \%)$ & $65(28.0 \%)$ & .034 \\
\hline \multicolumn{4}{|l|}{ Lung function tests } \\
\hline$\% \mathrm{FEV}_{1}$ & $809(77.7 \%)$ & $232(22.3 \%)$ & $<.001$ \\
\hline DLCO & $809(77.7 \%)$ & $232(22.3 \%)$ & $<.001$ \\
\hline Pathologic staging & $\mathrm{n}=803$ & $\mathrm{n}=230$ & .885 \\
\hline Stage 0 & $4(0.6 \%)$ & $1(0.4 \%)$ & \\
\hline Stage I & $539(67.1 \%)$ & $148(64.3 \%)$ & \\
\hline Stage II & $170(21.2 \%)$ & $49(21.3 \%)$ & \\
\hline Stage III & $87(10.8 \%)$ & $30(13.0 \%)$ & \\
\hline Stage IV & $5(0.6 \%)$ & $2(0.9 \%)$ & \\
\hline Procedure performed & & & .880 \\
\hline Wedge & $132(16.3 \%)$ & $35(15.1 \%)$ & \\
\hline Segmentectomy & $34(4.2 \%)$ & $10(4.3 \%)$ & \\
\hline Lobectomy & $586(72.4 \%)$ & $166(71.6 \%)$ & \\
\hline Extended lobectomy & $18(2.2 \%)$ & $7(3.0 \%)$ & \\
\hline Pneumonectomy & $39(4.8 \%)$ & $14(6.0 \%)$ & \\
\hline \multicolumn{4}{|l|}{ Approach } \\
\hline VATS vs thoracotomy & & & $<.001$ \\
\hline VATS & $488(60.3 \%)$ & $109(47.0 \%)$ & \\
\hline Thoracotomy & $320(39.7 \%)$ & $123(53.0 \%)$ & \\
\hline Nonconverted vs converted & & & .022 \\
\hline Nonconverted & $771(95.3 \%)$ & $212(91.4 \%)$ & \\
\hline Converted & $38(4.7 \%)$ & $20(8.6 \%)$ & \\
\hline Resection margin & $\mathrm{n}=798$ & $\mathrm{n}=228$ & .175 \\
\hline R0 & $761(95.4 \%)$ & $215(94.3 \%)$ & \\
\hline R1 & $36(4.5 \%)$ & $11(4.8 \%)$ & \\
\hline R2 & $1(0.1 \%)$ & $2(0.9 \%)$ & \\
\hline Adverse events & $\mathrm{n}=809$ & $\mathrm{n}=232$ & \\
\hline No & $570(70.5 \%)$ & $55(23.7 \%)$ & $<.001$ \\
\hline Yes & $239(29.5 \%)$ & $177(76.3 \%)$ & \\
\hline Grade I vs none & $\mathrm{n}=619$ & $\mathrm{n}=80$ & \\
\hline No adverse event & $570(92.1 \%)$ & $55(68.8 \%)$ & $<.001$ \\
\hline Grade I only & $49(7.9 \%)$ & $25(31.2 \%)$ & \\
\hline Minor vs major & $\mathrm{n}=239$ & $\mathrm{n}=177$ & \\
\hline Minor (Grade I + II) & $184(77.0 \%)$ & $107(60.5 \%)$ & $<.001$ \\
\hline Major (Grade III + IV) & $55(23.0 \%)$ & $70(39.5 \%)$ & \\
\hline
\end{tabular}


TABLE 1. Continued

\begin{tabular}{lccc}
\hline & $\begin{array}{c}\text { Expected } \\
\text { LOS, } \mathbf{n}=\mathbf{8 0 9}\end{array}$ & $\begin{array}{c}\text { PLOS, } \\
\mathbf{n}=\mathbf{2 3 2}\end{array}$ & $\boldsymbol{P}$ value \\
\hline TM\&M grades & $\mathrm{n}=809$ & $\mathrm{n}=232$ & \\
No adverse event & $570(70.5 \%)$ & $55(23.7 \%)$ & $<.001$ \\
Grade I & $49(6.1 \%)$ & $25(10.8 \%)$ & \\
Grade II & $135(16.7 \%)$ & $82(35.3 \%)$ & \\
Grade III & $49(6.1 \%)$ & $54(23.3 \%)$ \\
Grade IV & $6(0.7 \%)$ & $16(6.9 \%)$ & \\
\hline
\end{tabular}

Mann-Whitney $U$ test used for all non-normal distributed continuous variables. Values in bold are statistically significant at $P<.05$. LOS, Length of stay; PLOS, prolonged length of stay; $M$, male; $F$, female; $C O P D$, chronic obstructive pulmonary disease; $\% F E V I$, forced expiratory volume for 1 second expressed as a $\%$ of the forced vital capacity; $D L C O$, diffusion capacity of the lung for carbon monoxide; VATS, video-assisted thoracoscopic surgery; $T M \& M$, Thoracic Morbidity \& Mortality.

The Ottawa Hospital between January 2008 and July 2015 were considered for inclusion. Pediatric patients younger than the age of 18 years, patients who underwent pulmonary resection for nonmalignant disease, and patients who suffered in-hospital mortality or were listed as having a Grade V AE (ie, mortality) were excluded. This study was approved by The Ottawa Hospital Research Ethics Board.

\section{Data Source and Data Collection}

Morbidity and mortality data were prospectively collected daily by senior thoracic surgical residents using an electronic TM\&M form. Lists of procedures and the associated AEs were compiled weekly and further reaffirmed by staff surgeons and residents. AEs were presented and discussed monthly at divisional morbidity and mortality conferences, which further ensured that all the collected data were as accurate and transparent as possible. $^{14}$

Additional data on patient demographics, comorbidities, preoperative investigations and cardiopulmonary assessment, pathologic staging, and LOS were retrieved from The Ottawa Hospital's electronic medical record system and retrospectively added to a TM\&M-derived database of patient information - the Thoracic Surgery Quality monitoring, Information management, and Clinical documentation system. The Thoracic Surgery Quality monitoring, Information management, and Clinical documentation system contains information on the type of surgery performed, surgical approach, and TM\&M-classified AEs. ${ }^{11}$

Patient demographics included patients' sex and age at the time of the surgery. Comorbidities were collected for diabetes, coronary artery disease, hypercholesterolemia, congestive heart failure, pulmonary hypertension, hypertension, peripheral vascular disease, renal failure, cerebrovascular history, and chronic obstructive pulmonary disease (COPD). Preoperative investigations included imaging studies, investigative procedures, and pulmonary function tests (PFTs). Forced expiratory volume for 1 second expressed as a percentage of the forced vital capacity $\left(\% \mathrm{FEV}_{1}\right)$ and diffusion capacity of the lung for carbon monoxide (DLCO) were values recorded from the PFT. $\% \mathrm{FEV}_{1}$ and DLCO were used because they have been shown to be predictive of morbidity and mortality after pulmonary resection. ${ }^{15}$ Pathologic staging and surgical margins were obtained from pathology reports on the resected tumor specimens. LOS data were calculated from patient record dates.

\section{Defining Procedure-Specific PLOS}

The primary outcome of this study was LOS, defined as the number of calendar days from the operation to hospital discharge. PLOS was defined as postoperative hospital stay greater than the 75 th percentile of the specific procedure-wedge resection 6 days, segmentectomy 6 days, lobectomy 7 days, extended lobectomy 8 days, pneumonectomy 10 days-that the
TABLE 2. Summary statistics for continuous variables and test of normality

\begin{tabular}{lc}
\hline \multicolumn{1}{c}{ Variable } & Mean \pm SD/median (IQR) \\
\hline All $(\mathrm{n}=1041)$ & \\
Age & $66.47 \pm 9.27$ \\
$\quad$ Lung function tests & \\
$\quad \% F_{1}$ & $79.26 \pm 18.54$ \\
$\quad$ DLCO & $71.67 \pm 16.02$ \\
Expected LOS $(\mathrm{n}=809)$ & \\
$\quad$ Age & $66.20 \pm 9.17$ \\
Lung function tests & \\
$\quad \%$ FEV & \\
$\quad$ DLCO & $70.49 \pm 18.23$ \\
PLOS (n $=232)$ & \\
Age & $67.42 \pm 9.57$ \\
Lung function tests & \\
$\quad \%$ FEV & \\
$\quad$ DLCO & $74.0(23)$ \\
\hline
\end{tabular}

$S D$, Standard deviation; $I Q R$, interquartile range; $\% F E V_{l}$, forced expiratory volume for 1 second expressed as a $\%$ of the forced vital capacity; $D L C O$, diffusion capacity of the lung for carbon monoxide; $L O S$, length of stay; $P L O S$, prolonged length of stay.

patient underwent. ${ }^{16}$ We defined extended lobectomy to be pulmonary resection greater than single-lobe resection and less than pneumonectomy (ie, lobectomy + wedge). Because the postoperative recovery pathways employed can vary for patients between surgical centers and depending on the patient's extent of lung resection, it is more accurate to categorize PLOS as the top 75th percentile of the patients categorized by procedure in the center, as other have done. ${ }^{17}$ In addition, for the duration of this study, our postoperative pathways were defined by procedure, regardless of surgical approach.

\section{Classification of Postoperative AEs}

Postoperative AEs were reported using the TM\&M classification system. Based on the Clavien-Dindo classification system, the TM\&M defines all thoracic surgery AEs into the following grades: Grade I AE, requiring no pharmacologic intervention (eg, transient atrial fibrillation); Grade II AE, requiring pharmacologic intervention only (eg, atrial fibrillation requiring beta-blocker); Grade III AE, requiring further intervention without (IIIA) (eg, atrial fibrillation requiring cardioversion or device) or with general anesthesia (IIIB) (eg, atrial fibrillation requiring operative intervention under general anesthesia); Grade IV, AE requiring single-organ (IVA) or multiorgan life support (IVB); and Grade V, AE causing death. ${ }^{7}$ The TM\&M defines Grade I prolonged alveolar air leak as air leak lasting $>5$ days or air leak present on discharge from hospital with planned followup $>$ POD 6 with no intervention required.

\section{Statistical Analysis}

Comparison of baseline demographics, comorbidities, and operative variables between the expected LOS and PLOS cohorts were analyzed with the independent sample $t$ test or Mann-Whitney $U$ test for continuous variables and the $\chi^{2}$ test or Fisher exact test for categorical variables, respectively. Continuous data were assessed for normality via the Shapiro-Wilk test and reported as either mean (standard deviation) or median (interquartile range [IQR]) depending on the result of the normality test. Univariable and multivariable logistic regression models were built to evaluate the association of patient- and treatment-related parameters on odds ratios (ORs) with $95 \%$ confidence intervals (95\% CIs) for 
TABLE 3. Consecutive pulmonary resection for cancer cases categorized base on procedure, mortality status, LOS status, and AE grade

\begin{tabular}{|c|c|c|c|c|c|c|}
\hline \multirow{2}{*}{$\begin{array}{c}\begin{array}{c}\text { Total pulmonary } \\
\text { resection }\end{array} \\
\mathrm{n}=1062\end{array}$} & \multicolumn{2}{|c|}{ Procedure } & \multicolumn{2}{|c|}{ LOS status } & \multicolumn{2}{|c|}{ AE grade } \\
\hline & Wedge resection & $167(15.7 \%)$ & $\begin{array}{l}\text { Expected LOS } \\
(\text { LOS } \leq 6 \mathrm{~d})\end{array}$ & $132(79.0 \%)$ & No AE & $106(80.0 \%)$ \\
\hline & & & & & Grade I & $5(3.8 \%)$ \\
\hline & & & & & Grade II & $12(9.1 \%)$ \\
\hline & & & & & Grade III & $7(5.3 \%)$ \\
\hline & & & & & Grade IV & $2(1.5 \%)$ \\
\hline & & & $\begin{array}{l}\text { PLOS } \\
(\text { LOS }>6 \mathrm{~d})\end{array}$ & $35(21.0 \%)$ & No AE & $13(37.0 \%)$ \\
\hline & & & & & Grade I & $3(8.6 \%)$ \\
\hline & & & & & Grade II & $8(22.9 \%)$ \\
\hline & & & & & Grade III & $9(25.0 \%)$ \\
\hline & & & & & Grade IV & $2(5.7 \%)$ \\
\hline & Segmentectomy & $44(4.1 \%)$ & $\begin{array}{l}\text { Expected LOS } \\
(\text { LOS } \leq 6 \mathrm{~d})\end{array}$ & $34(77.3 \%)$ & No AE & $31(91.2 \%)$ \\
\hline & & & & & Grade I & $1(2.9 \%)$ \\
\hline & & & & & Grade II & $1(2.9 \%)$ \\
\hline & & & & & Grade III & $1(2.9 \%)$ \\
\hline & & & & & Grade IV & $0(0 \%)$ \\
\hline & & & $\begin{array}{l}\text { PLOS } \\
(\operatorname{LOS}>6 \mathrm{~d})\end{array}$ & $10(22.7 \%)$ & No AE & $5(50.0 \%)$ \\
\hline & & & & & Grade I & $2(20.0 \%)$ \\
\hline & & & & & Grade II & $3(30.0 \%)$ \\
\hline & & & & & Grade III & $0(0 \%)$ \\
\hline & & & & & Grade IV & $0(0 \%)$ \\
\hline & Lobectomy & $766(72.1 \%)$ & $\begin{array}{l}\text { Expected LOS } \\
(\text { LOS } \leq 7 \mathrm{~d})\end{array}$ & $586(76.5 \%)$ & No AE & $402(68.6 \%)$ \\
\hline & & & & & Grade I & $37(6.2 \%)$ \\
\hline & & & & & Grade II & $105(17.9 \%)$ \\
\hline & & & & & Grade III & $39(6.7 \%)$ \\
\hline & & & & & Grade IV & $3(0.5 \%)$ \\
\hline & & & $\begin{array}{l}\text { PLOS } \\
(\operatorname{LOS}>7 \mathrm{~d})\end{array}$ & $166(21.7 \%)$ & No AE & $34(20.5 \%)$ \\
\hline & & & & & Grade I & $20(12.0 \%)$ \\
\hline & & & & & Grade II & $64(38.6 \%)$ \\
\hline & & & & & Grade III & $38(22.9 \%)$ \\
\hline & & & & & Grade IV & $10(6.0 \%)$ \\
\hline & & & Mortality & $14(1.8 \%)$ & & \\
\hline & Extended lobectomy & $26(2.4 \%)$ & $\begin{array}{l}\text { Expected LOS } \\
(\text { LOS } \leq 8 \mathrm{~d})\end{array}$ & $18(69.2 \%)$ & No AE & $7(38.9 \%)$ \\
\hline & & & & & Grade I & $3(16.7 \%)$ \\
\hline & & & & & Grade II & $7(38.9 \%)$ \\
\hline & & & & & Grade III & $1(5.6 \%)$ \\
\hline & & & & & Grade IV & $0(0 \%)$ \\
\hline & & & $\begin{array}{l}\text { PLOS } \\
(\text { LOS }>8 d)\end{array}$ & $7(26.9 \%)$ & No AE & $2(28.6 \%)$ \\
\hline
\end{tabular}


TABLE 3. Continued

\begin{tabular}{|c|c|c|c|c|c|c|}
\hline \multirow[t]{2}{*}{$\begin{array}{c}\text { Total pulmonary } \\
\text { resection }\end{array}$} & \multicolumn{2}{|c|}{ Procedure } & \multicolumn{2}{|c|}{ LOS status } & \multicolumn{2}{|c|}{ AE grade } \\
\hline & & & & & Grade I & $0(0 \%)$ \\
\hline & & & & & Grade II & $2(28.6 \%)$ \\
\hline & & & & & Grade III & $3(42.9 \%)$ \\
\hline & & & & & Grade IV & $0(0 \%)$ \\
\hline & & & Mortality & $1(3.8 \%)$ & & \\
\hline & Pneumonectomy & $59(5.5 \%)$ & $\begin{array}{l}\text { Expected LOS } \\
(\text { LOS } \leq 10 \mathrm{~d})\end{array}$ & $39(66.1 \%)$ & No AE & $24(61.5 \%)$ \\
\hline & & & & & Grade I & $3(7.7 \%)$ \\
\hline & & & & & Grade II & $10(25.6 \%)$ \\
\hline & & & & & Grade III & $1(2.6 \%)$ \\
\hline & & & & & Grade IV & $1(2.6 \%)$ \\
\hline & & & $\begin{array}{l}\text { PLOS } \\
(\text { LOS >10 d) }\end{array}$ & $14(23.7 \%)$ & No AE & $1(7.1 \%)$ \\
\hline & & & & & Grade I & $0(0 \%)$ \\
\hline & & & & & Grade II & $5(35.7 \%)$ \\
\hline & & & & & Grade III & $4(28.6 \%)$ \\
\hline & & & & & Grade IV & $4(28.6 \%)$ \\
\hline & & & Mortality & $6(10.2 \%)$ & & \\
\hline
\end{tabular}

LOS, Length of stay; $A E$, adverse event; PLOS, prolonged length of stay.

PLOS. The multivariable logistic regression model was created with stepwise variable selection using SPSS binary logistic function with the forward: conditional method. Missing $\% \mathrm{FEV}_{1}(\mathrm{n}=97)$ and DLCO $(\mathrm{n}=167)$ data were added using multivariable imputation. A new data set was created using the Mersenne Twister random number generator to impute missing data values. The constraints were set to the observed minimum and maximum from the collected data- $\% \mathrm{FEV}_{1}(21,169)$ and DLCO $(28,146)$. The model was assessed using the Omnibus test. $P$ value $<.05$ was considered statistically significant. Data analyses were conducted with IBM SPSS Statistics Version 18 software (SPSS, Chicago, Ill)

\section{RESULTS}

\section{Patient Demographics and Clinical Characteristics}

A total of 1062 cases of consecutive pulmonary resection for cancer were identified, and of those, $21(2.0 \%)$ were excluded due to in-hospital patient mortality, leaving 1041 cases meeting inclusion criteria for this study. A total of $97(9.3 \%)$ missing $\% \mathrm{FEV}_{1}$ and $167(16.0 \%)$ missing DLCO data were generated by the use of multiple imputation and were included in baseline analyses. A summary of patient characteristics in expected LOS versus PLOS group can be found in Table 1. In the cohort of patients with PLOS, there was a significant increased proportion of male patients $(51.3 \%$ vs $42.4 \%)$, and comorbid illnesses, including history of coronary artery disease $(20.6 \%$ vs $15.2 \%)$, pulmonary hypertension $(0.9 \%$ vs $0 \%)$, congestive heart failure $(0.9 \%$ vs $0 \%)$, COPD (28.0\% vs $21.4 \%)$, and lower $\% \mathrm{FEV}_{1}$ and DLCO.
A test of normality was performed for all continuous variables, and the result is available in Table 2.

\section{Volume of Procedures Performed}

The majority of the pulmonary resections were lobectomies $(\mathrm{n}=766 ; 72.1 \%)$. A breakdown of proportion of procedures performed is available in Table 3 . Video-assisted thoracoscopic surgery (VATS) was favored for less-extensive lung resection (595/963 cases; 61.8\%), whereas open operations were performed for the majority of extended lobectomies (19/25 cases; 76.0\%) and almost all pneumonectomies (52/53 cases; 98.1\%). In the PLOS group, there were significantly less VATS $(47.0 \%$ vs $60.3 \%, P<.01)$, more thoracotomy $(44.4 \%$ vs $35.0 \%$, $P<.01$ ), and more intraoperative conversion from VATS to thoracotomy $(8.6 \%$ vs $4.7 \%, P<.01)$ performed (Table 1).

\section{Procedure-Specific Postoperative PLOS}

LOS ranged from 1 to 66 days; the median LOS in patients without PLOS was 4 (IQR 2) days and the median PLOS was 11 (IQR 7) days. Based on the definition of PLOS as greater than or equal to the 75th percentile LOS for each procedure type, 232 patients $(22.3 \%)$ were categorized as having PLOS. The PLOS group was not made up of the exactly top 25th percentile because LOS was reported as days in whole numbers. 
TABLE 4. Ten most common AE in expected LOS and PLOS groups

\begin{tabular}{|c|c|c|c|}
\hline & Total AE & Ten most common AE & $\begin{array}{c}\text { n }(\% \text { of } \\
\text { total AE) }\end{array}$ \\
\hline \multirow{10}{*}{$\begin{array}{l}\text { Expected } \\
\qquad \begin{array}{l}\text { LOS } \\
(n=809)\end{array}\end{array}$} & $\mathrm{n}=229$ & Atrial arrhythmia & $67(29.3)$ \\
\hline & & Prolonged air leak & $44(19.2)$ \\
\hline & & Subcutaneous emphysema & $21(9.2)$ \\
\hline & & Confusion & $11(4.8)$ \\
\hline & & Atelectasis & $10(4.4)$ \\
\hline & & Pneumothorax & $9(3.9)$ \\
\hline & & Pneumonia & $7(3.1)$ \\
\hline & & Urinary retention & $7(3.1)$ \\
\hline & & Urinary tract infection & $7(3.1)$ \\
\hline & & Pleural effusion & $6(2.6)$ \\
\hline \multirow{10}{*}{$\begin{array}{l}\text { PLOS } \\
\qquad(\mathrm{n}=232)\end{array}$} & $\mathrm{n}=177$ & Prolonged air leak & $54(30.5)$ \\
\hline & & Atrial arrhythmia & $28(15.8)$ \\
\hline & & Pneumonia & $11(6.2)$ \\
\hline & & Subcutaneous emphysema & $9(5.1)$ \\
\hline & & Confusion & $7(4.0)$ \\
\hline & & Myocardial infarction & $7(4.0)$ \\
\hline & & Atelectasis & $5(2.8)$ \\
\hline & & Pleural effusion & $5(2.8)$ \\
\hline & & Empyema & $4(2.3)$ \\
\hline & & Bronchopleural fistula & $3(1.7)$ \\
\hline
\end{tabular}

$A E$, Adverse event; $L O S$, length of stay; PLOS, prolonged length of stay.

\section{Postoperative TM\&M Classification}

A total of $416(40.0 \%)$ patients had 1 or more postoperative AEs. The PLOS group had a significantly greater proportion of AEs $(76.2 \%$ vs $29.5 \%, P<.01)$, Grade I AE $(10.8 \%$ vs $6.1 \%, P<.01)$, Grade II AE $(35.3 \%$ vs $16.7 \%, P<.01)$, Grade III AE $(23.3 \%$ vs $6.1 \%, P<.01)$, and Grade IV AE $(6.9 \%$ vs $0.7 \%$, $P<.01)$ (Table 1). The most common AEs in expected LOS and PLOS groups are listed in Table 4.

\section{Univariable Analyses to Identify Factors Associated With PLOS After Pulmonary Resection}

Univariable logistic regression models were used to analyze perioperative factors associated with PLOS. Significant factors included (in OR; 95\% CI) male sex (1.4; 1.1-1.9), having a history of coronary artery disease $(1.5 ; 1.0-2.1)$ or COPD $(1.4 ; 1.0-2.0)$, lesser value of $\%$ $\mathrm{FEV}_{1}(0.99 ; 0.98-0.99)$ or DLCO $(0.98 ; 0.98-0.98)$, more invasive surgical approach-either open thoracotomy $(1.7 ; 1.3-2.3)$ or those requiring intraoperative conversion (1.9; 1.1-3.4) and any stage of AE—stage I (5.3; 3.1-9.2), stage II $(6.3 ; 4.3-9.3)$, stage III $(11.4 ; 7.1-18.4)$, or stage IV $(27.6 ; 10.4-73.5)$ (Table 5).
TABLE 5. Results of univariable logistic regression to identify perioperative factors associated with PLOS

\begin{tabular}{|c|c|c|}
\hline Variable & Odds ratios $(95 \%$ CI $)$ & $P$ value \\
\hline \multicolumn{3}{|l|}{ Demographics } \\
\hline \multicolumn{3}{|l|}{ Sex } \\
\hline Female & 1.00 & \\
\hline Male & $1.43(1.07-1.92)$ & .016 \\
\hline Age & $1.01(1.00-1.03)$ & .079 \\
\hline \multicolumn{3}{|l|}{ Comorbidities } \\
\hline Diabetes & $0.99(0.67-1.46)$ & .965 \\
\hline Coronary artery disease & $1.46(1.00-2.11)$ & .048 \\
\hline Hypercholesterolemia & $1.08(0.75-1.54)$ & .683 \\
\hline Hypertension & $0.97(0.72-1.30)$ & .819 \\
\hline Pulmonary hypertension & Insufficient incidence & .999 \\
\hline $\begin{array}{l}\text { Peripheral vascular } \\
\text { disease }\end{array}$ & $1.23(0.69-2.17)$ & .484 \\
\hline Congestive heart failure & Insufficient incidence & .999 \\
\hline Renal failure & $0.29(0.04-2.22)$ & .232 \\
\hline Cerebrovascular history & $1.06(0.51-2.18)$ & .876 \\
\hline COPD & $1.43(1.03-2.00)$ & .035 \\
\hline \multicolumn{3}{|l|}{ Lung function tests } \\
\hline$\%$ FEV1 & $0.985(0.981-0.988)$ & $<.001$ \\
\hline DLCO & 0.979 (0.976-0.983) & $<.001$ \\
\hline \multicolumn{3}{|l|}{ Operative characteristics } \\
\hline \multicolumn{3}{|l|}{ Procedure performed } \\
\hline Lobectomy & 1.00 & \\
\hline Wedge & $0.94(0.62-1.41)$ & .752 \\
\hline Segmentectomy & $1.04(0.50-2.15)$ & .919 \\
\hline Extended lobectomy & $1.37(0.57-3.34)$ & .485 \\
\hline Pneumonectomy & $1.27(0.67-2.39)$ & .464 \\
\hline \multicolumn{3}{|l|}{ Approach } \\
\hline \multicolumn{3}{|c|}{ Conversion vs nonconversion } \\
\hline Nonconversion & 1.00 & \\
\hline Conversion & $1.91(1.09-3.36)$ & .024 \\
\hline \multicolumn{3}{|l|}{ VATS vs open } \\
\hline VATS & 1.00 & \\
\hline Open & $1.72(1.29-2.31)$ & $<.001$ \\
\hline \multicolumn{3}{|l|}{ Resection margin } \\
\hline R0 & 1.00 & \\
\hline $\mathrm{R} 1$ & $1.18(0.60-2.31)$ & .633 \\
\hline $\mathrm{R} 2$ & Insufficient incidence & .999 \\
\hline \multicolumn{3}{|l|}{ Pathologic staging } \\
\hline Stage 0 & 1.00 & \\
\hline Stage I & $0.82(0.09-7.98)$ & .867 \\
\hline Stage II & $0.87(0.09-8.50)$ & .901 \\
\hline Stage III & $1.03(0.10-10.33)$ & .977 \\
\hline Stage IV & $1.20(0.07-19.63)$ & .898 \\
\hline \multicolumn{3}{|l|}{ Adverse events } \\
\hline None & 1.00 & \\
\hline Grade I & $5.29(3.03-9.22)$ & $<.001$ \\
\hline Grade II & $6.30(4.26-9.30)$ & $<.001$ \\
\hline Grade III & $11.42(7.10-18.38)$ & $<.001$ \\
\hline Grade IV & $27.64(10.39-73.51)$ & $<.001$ \\
\hline
\end{tabular}

Values in bold are statistically significant at $P<.05 . C I$, Confidence interval; $C O P D$, chronic obstructive pulmonary disease; $\% F E V_{l}$, forced expiratory volume for 1 second expressed as a \% of the forced vital capacity; $D L C O$, diffusion capacity of the lung for carbon monoxide; VATS, video-assisted thoracoscopic surgery. 


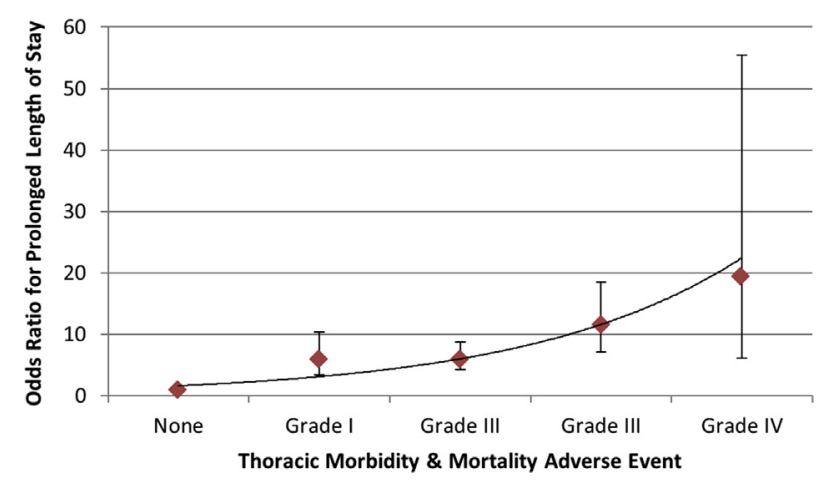

FIGURE 1. Association between Thoracic Morbidity \& Mortality adverse event grade and odds ratio for prolonged length of stay.

\section{Multivariable Analyses to Identify Factors} Associated With PLOS After Pulmonary Resection

Multivariable logistic regression using stepwise variable selection was performed to identify perioperative factors associated with PLOS. Significant factors included (in OR; 95\% CI): lower DLCO (0.99; 0.98-0.99); surgical approach: thoracotomy $(1.8 ; 1.3-2.5)$ versus VATS; and presence of any postoperative AE: Grade I (5.8; 3.3-10.2), Grade II (6.0; 4.0-8.9); Grade III (11.4; 7.0-18.7), and Grade IV (19.4; 7.1-55.2) (Figure 1). The final model had an Omnibus test of model coefficient $P$ value $=.03$ (Table 6). Sensitivity analysis was performed excluding patients with missing $\% \mathrm{FEV}_{1}$ and DLCO data, and the resulting estimates of effect did not change significantly (Table 7).

\section{DISCUSSION}

Our study identified several factors associated with increased odds of PLOS (defined as staying longer than

TABLE 6. Results of multivariable logistic regression model for odds ratio of having PLOS

\begin{tabular}{lcc}
\hline \multicolumn{1}{c}{ Variable } & Odds ratios $(\mathbf{9 5} \% \mathbf{C I})$ & $\boldsymbol{P}$ value \\
\hline Lung function tests & & $\mathbf{. 0 0 5}$ \\
$\quad$ DLCO & $0.985(0.975-0.995)$ & \\
Approach (VATS vs open) & & \\
$\quad$ VATS & 1.00 & $\mathbf{. 0 0 1}$ \\
$\quad$ Open & $1.77(1.26-2.48)$ & \\
Adverse events & 1.00 & $<.001$ \\
$\quad$ None & $5.80(3.28-10.24)$ & $<.001$ \\
Grade I & $5.97(4.02-8.88)$ & $<.001$ \\
Grade II & $11.44(6.99-18.71)$ & $<.001$ \\
Grade III & $19.40(7.07-55.18)$ & $\mathbf{. 0 3 2}$ \\
Grade IV & .271 \\
\hline Omnibus tests of model coefficients $P$ value & \\
Hosmer and Lemeshow test $P$ value & \\
\hline
\end{tabular}

Congestive heart failure not included in final model due to low number of patients recorded to have the condition at the time of surgery $(\mathrm{n}=2)$. Values in bold are statistically significant at $P<.05$. CI, Confidence interval; $D L C O$, diffusion capacity of the lung for carbon monoxide; VATS, video-assisted thoracoscopic surgery.
TABLE 7. Sensitivity analysis of multivariable logistic regression performed excluding patients with missing PFT data

\begin{tabular}{lcc}
\hline \multicolumn{1}{c}{ Variable } & Odds ratios $(\mathbf{9 5} \% \mathbf{C I})$ & $\boldsymbol{P}$ value \\
\hline $\begin{array}{l}\text { Lung function tests } \\
\quad \text { DLCO }\end{array}$ & $0.982(0.970-0.994)$ & $\mathbf{. 0 0 4}$ \\
$\begin{array}{l}\text { Approach (VATS vs open) } \\
\quad \text { VATS }\end{array}$ & 1.00 & \\
$\quad$ Open & $2.04(1.39-2.99)$ & $\mathbf{. 0 0 1}$ \\
Adverse events & 1.00 & \\
$\quad$ None & $8.64(4.68-15.94)$ & $<.001$ \\
Grade I & $6.17(3.88-9.81)$ & $<.001$ \\
Grade II & $10.31(5.88-18.10)$ & $<.001$ \\
Grade III & $23.62(7.66-72.89)$ & $<.001$ \\
$\quad$ Grade IV & $\mathbf{. 0 2 9}$ \\
Omnibus tests of model coefficients $P$ value & $\mathbf{. 0 4 8}$ \\
\hline Hosmer and Lemeshow test $P$ value & \\
\hline
\end{tabular}

Congestive heart failure not included in final model due to low number of patients recorded to have the condition at the time of surgery $(\mathrm{n}=2)$. Values in bold are statistically significant at $P<.05$. $C I$, Confidence interval; $D L C O$, diffusion capacity of the lung for carbon monoxide; VATS, video-assisted thoracoscopic surgery.

the 75th percentile for their surgical procedure) after pulmonary resection for lung cancer. These factors included lower DLCO, thoracotomy, and presence of any postoperative $\mathrm{AE}$ as defined by the TM\&M classification system. Patient's sex, age, comorbidities, $\% \mathrm{FEV}_{1}$, resection margin, and pathologic stage were not found to have significant association with PLOS after pulmonary resection with curative intent.

A recent study of 490 patients from Institutional Society of Thoracic Surgery data also found DLCO as a factor for PLOS. ${ }^{18}$ In addition, previous studies also demonstrated that decreasing DLCO is associated with increased rate of pulmonary complications. ${ }^{19}$ Specifically, DLCO has a greater correlation with postoperative mortality than $\% \mathrm{FEV}_{1} \cdot{ }^{20}$ This correlation in morbidity and mortality also could be indirectly reflected in PLOS. In regard to surgical approach, previous studies have shown that VATS resulted in a significantly lower LOS than the thoracotomy approach in patients undergoing lobectomy. ${ }^{21-23}$ Both approaches result in a similar rate of 5 -year survival, ${ }^{24}$ but VATS appears to offer the benefit of less postoperative $\mathrm{AE}$, reduced pain, earlier mobility, and discharge.

Before the TM\&M classification system was used to identify perioperative factors for increased odds of PLOS in pulmonary resection patients, the effect of minor AEs on patients has been controversial. Several previous studies have delineated predictive factors for PLOS using large databases of patients, such as the Society of Thoracic Surgeons' General Thoracic Surgery Database, ${ }^{1}$ the American College of Surgeons' National Surgical Quality Improvement Program, ${ }^{3}$ or stand-alone institutional databases. $^{4-6}$ Most studies did not classify or report the severity of AEs or simply omitted minor AEs 


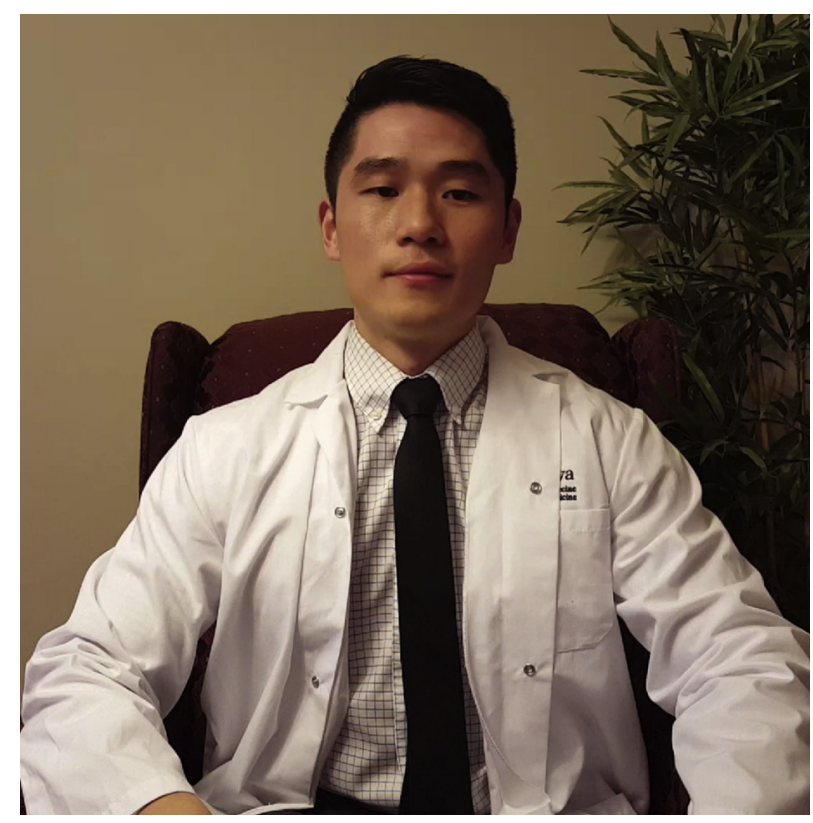

VIDEO 1. Explanation of the Thoracic Morbidity \& Mortality system and the important effect of minor adverse events on patient length of stay. Video available at: http://www.jtcvsonline.org/article/S00225223(17)32135-9/fulltext.

altogether. ${ }^{3,4}$ However, our study showed that even Grade I AEs significantly increased the odds of PLOS $(95 \% \mathrm{CI})$ by 5.8 times (3.3-10.2). The most common Grade I AEs were air leaks ( $62 \%$ of Grade I AEs). We found the presence of any $\mathrm{AE}$ has a greater OR than surgical approach used, such as thoracotomy $(1.8 ; 1.3-2.5)$. AEs experienced by patients postoperatively can prolong LOS due to required treatments and interventions, delayed recovery, and increased time needed for observation. Other previous studies have also found an association between AEs and PLOS in patients who underwent lung resection. ${ }^{1,3,5}$ Thus, reducing the rate of postoperative AEs may represent an important modifiable means to decrease LOS. In addition, decreased LOS may also lead to decreased costs. A recent study on factors associated with postoperative costs after anatomic lung resection without major AEs showed that even minor AEs (TM\&M Grade I and II) are significantly associated with increased cost. ${ }^{10}$

We used different 75 th percentile cut-off marks for PLOS for different pulmonary resections because increasing extent of pulmonary resection is a known risk factor for PLOS. Other studies have found that pneumonectomy was associated with a greater risk of major AEs and PLOS. ${ }^{17}$ The postoperative care pathway in the division has been largely determined by the type of procedure and extent of pulmonary resection.

A similar study using data from 4979 lobectomies for lung cancer found a greater number of significant predictors of PLOS. The predictors were age, Eastern Cooperative Oncology Group score, male sex, American Society of
Anesthesiologists score, insulin-dependent diabetes, renal dysfunction, induction therapy, $\% \mathrm{FEV}_{1}$, and smoking status. ${ }^{1}$ However, the study used a more extended cut-off for PLOS at 14 days or longer, which included only $7 \%$ of the patients. They also did not account for the variable extent of pulmonary resections. Despite this, the National Surgical Quality Improvement Program study found similar results, where older age, thoracotomy, and various complications to be significant for increasing the risk of PLOS. ${ }^{3}$ Other additional studies looking at the effect of postoperative AEs on LOS also found that the presence of AEs was associated with PLOS. ${ }^{1,4,5}$ However, no previous studies used an AEs severity grading system similar to TM\&M. The reporting of AEs in the literature is lacking. For example, a single-center study of 7457 noncardiac surgical patients, albeit not specific to thoracic surgery, found that AEs occurred only in $6.9 \%,{ }^{4}$ which was much lower than the $40.0 \% \mathrm{AE}$ rate found in our study. Minor AEs may not be included in the other studies.

Our study has several limitations. It is a single-center study, and practice patterns governing LOS vary greatly between institutions and health care systems. For example, flexibility for deviation from clinical pathways may vary from institution to institution. As a more specific example, response to prolonged air leaks can be managed without prolonged admission if there is a lower or rigid threshold to send patients home with chest tubes. Second, we were unable to collect data on variables that other studies have found to be significant, such as preoperative smoking status, induction status, and performance status. Some of the retrospective data obtained from patient charts have incomplete data set (eg, PFTs). However, the missing PFT data $(12 \%)$ were substituted using multiple imputation methods and data analysis was checked with sensitivity analysis. In addition, despite the fact that TM\&M data were collected in a prospective manner, this study remained a retrospective review and was subjected to difficulty controlling bias and establishing temporal cause/effect relationships. Finally, it should be noted that enhanced recovery after surgery (ERAS) pathways have been demonstrated to significantly reduce LOS in a thoracic surgery population. ${ }^{25}$ During the inclusion period of our study, the ERAS pathway was not in use. However, our division is currently in the process of implementing ERAS pathway after all thoracic surgery.

Our study has several strengths. First, it included for the first time the use of an AE severity classification system to compare the relative impact of AEs on LOS. The TM\&M data collection was performed daily and went through a weekly review by residents and staff. ${ }^{14}$ We perceive the 75th percentile procedure-specific definition for PLOS was clinically relevant, reflecting the majority of patients, and helped reflect expected procedure-specific differences in LOS. Lastly, the patients were risk adjusted for their 
sex, age, comorbidities, and preoperative lung function scores.

\section{Implications and Future Directions}

Preventing AEs, including minor ones, may be helpful in reducing LOS. Factors indicating patients with high odds for PLOS could be provided targeted customized pre- and postoperative recovery pathways to minimize their stay and improve their hospital experience. Particularly, our finding of minor AEs being a factor for increased odds of PLOS further validates the importance of tracking all AEs, including minor ones. In addition, due to the interplaying relationship found between AEs, LOS, and costs, minimizing AEs and LOS may also lower the cost of care. ${ }^{10,26,27}$ Similar to TM\&M, the adaptation of the original Clavien-Dindo AE classification system has been used in various other surgical subspecialties such as orthopedics, urology, and general surgery. ${ }^{28-30}$ It would be interesting to explore whether the same relationship between AE classification and PLOS exists in other surgical subspecialties.

\section{CONCLUSIONS}

Our study identified perioperative factors significantly associated with increased odds of PLOS, namely lower DLCO, thoracotomy, and the presence of any postoperative $\mathrm{AE}$ as reported by $\mathrm{TM} \& \mathrm{M}$, including minor $\mathrm{AEs}$ such as Grade I, which require no new intervention, and Grade II, which require a new medication therapy only. This information may be useful for discharge planning where patients without identified factors may have fast tracking recovery pathway and patients with identified factors for PLOS can have additional support arranged to expedite return to function (Video 1).

\section{Conflict of Interest Statement}

Authors have nothing to disclose with regard to commercial support.

We acknowledge Caitlin Anstee, Database and Software Manager, Division of Thoracic Surgery, The Ottawa Hospital, for her help with data acquisition and data management throughout the duration of this study.

\section{References}

1. Wright CD, Gaissert HA, Grab JD, O'Brien SM, Peterson ED, Allen MS Predictors of prolonged length of stay after lobectomy for lung cancer: a Society of Thoracic Surgeons General Thoracic Surgery Database risk-adjustment model. Ann Thorac Surg. 2008;85:1857-65.

2. Farjah F, Lou F, Rusch VW, Rizk NP. The quality metric prolonged length of stay misses clinically important adverse events. Ann Thorac Surg. 2012; 94:881-7.

3. Khan NA, Quan H, Bugar JM, Lemaire JB, Brant R, Ghali WA. Association of postoperative complications with hospital costs and length of stay in a tertiary care center. J Gen Intern Med. 2006;21:177-80.
4. DeLuzio MR, Keshava HB, Wang Z, Boffa DJ, Detterbeck FC, Kim AW. A model for predicting prolonged length of stay in patients undergoing anatomical lung resection: a National Surgical Quality Improvement Program (NSQIP) database study. Interact Cardiovasc Thorac Surgy. 2016;23:208-15.

5. Lugg ST, Agostini PJ, Tikka T, Kerr A, Adams K, Bishay E, et al. Long-term impact of developing a postoperative pulmonary complication after lung surgery. Thorax. 2016;71:171-6.

6. Parsons JA, Johnston MR, Slutsky AS. Predicting length of stay out of hospital following lung resection using preoperative health status measures. Qual Life Res. 2003;12:645-54.

7. Seely AJ, Ivanovic J, Threader J, Al-Hussaini A, Al-Shehab D, Ramsay T, et al. Systematic classification of morbidity and mortality after thoracic surgery. Ann Thorac Surg. 2010;90:936-42.

8. Ivanovic J, Anstee C, Ramsay T, Gilbert S, Maziak DE, Shamji FM, et al. Using surgeon-specific outcome reports and positive deviance for continuous quality improvement. Ann Thorac Surg. 2015;100:1188-94.

9. Brunelli A, Drosos P, Dinesh P, Ismail H, Bassi V. The severity of complications is associated with postoperative costs after lung resection. Ann Thorac Surg. 2017;103:1641-6.

10. Brunelli A, Drosos P, Ismail H, Pompili C, Bassi V. Factors associated with postoperative costs following anatomic lung resections without major complications. Eur J Cardiothorac Surg. 2017;51:230-5.

11. Salati M, Pompili C, Refai M, Xiumè F, Sabbatini A, Brunelli A. The use of the Thoracic Morbidity and Mortality system for the internal analysis of performance: a case-matched temporal audit. Eur J Cardiothorac Surg. 2014; 45:859-63.

12. Salati M, Refai M, Pompili C, Xiumè F, Sabbatini A, Brunelli A, et al. Major morbidity after lung resection: a comparison between the European Society of Thoracic Surgeons Database system and the Thoracic Morbidity and Mortality system. J Thorac Dis. 2013;5:217-22.

13. Infante M, Chiesa G, Solomon D, Morenghi E, Passera E, Lutman FR, et al. Surgical procedures in the DANTE trial: a randomized study of lung cancer early detection with spiral computed tomography: Comparative analysis in the screening and control arm. J Thorac Oncol. 2011;6:327-35.

14. Ivanovic J, Al-Hussaini A, Al-Shehab D, Threader J, Villeneuve PJ, Ramsay T, et al. Evaluating the reliability and reproducibility of the Ottawa Thoracic Morbidity and Mortality classification system. Ann Thorac Surg. 2011;91: 387-93.

15. Gould G, Pearce A. Assessment of suitability for lung resection. CEACCP. 2006; 6:97-100.

16. Collins TC, Daley J, Henderson WH, Khuri SF. Risk factors for prolonged length of stay after major elective surgery. Ann Surg. 1999;230:251.

17. Powell ES, Pearce AC, Cook D, Davies P, Bishay E, Bowler GM, et al. UK pneumonectomy outcome study (UKPOS): a prospective observational study of pneumonectomy outcome. J Cardiothorac Surg. 2009;4:1.

18. Sancheti MS, Melvan JN, Medbery RL, Fernandez FG, Gillespie TW, Li Q, et al. Outcomes after surgery in high-risk patients with early stage lung cancer. Ann Thorac Surg. 2016;101:1043-51.

19. Wyser C, Stulz P, Solèr M, Tamm M, Müller-Brand J, Habicht J, et al. Prospective evaluation of an algorithm for the functional assessment of lung resection candidates. Am J Respir Crit Care Med. 1999;159:1450-6.

20. Ferguson MK, Little L, Rizzo L, Popovich KJ, Glonek GF, Leff A, et al. Diffusing capacity predicts morbidity and mortality after pulmonary resection. J Thorac Cardiovasc Surg. 1988;96:894-900.

21. Paul S, Sedrakyan A, Chiu YL, Nasar A, Port JL, Lee PC, et al. Outcomes after lobectomy using thoracoscopy vs thoracotomy: a comparative effectiveness analysis utilizing the Nationwide Inpatient Sample database. Eur J Cardiothorac Surg. 2013;43:813-7.

22. Bernard A, Ferrand L, Hagry O, Benoit L, Cheynel N, Favre JP. Identification of prognostic factors determining risk groups for lung resection. Ann Thorac Surg. 2000;70:1161-7.

23. Demmy TL, Nwogu C. Is video-assisted thoracic surgery lobectomy better? Quality of life considerations. Ann Thorac Surg. 2008;85:S719-28.

24. Flores RM, Park BJ, Dycoco J, Aronova A, Hirth Y, Rizk NP, et al. Lobectomy by video-assisted thoracic surgery (VATS) versus thoracotomy for lung cancer. $J$ Thorac Cardiovasc Surg. 2009;138:11-8.

25. Scarci M, Solli P, Bedetti B. Enhanced recovery pathway for thoracic surgery in the UK. J Thorac Dis. 2016;8(suppl 1):S78.

26. Varela G, Jiménez MF, Novoa N, Aranda JL. Estimating hospital costs attributable to prolonged air leak in pulmonary lobectomy. Eur J Cardiothorac Surg. 2005;27:329-33. 
27. Lacin T, Swanson S. Current costs of video-assisted thoracic surgery (VATS) lobectomy. J Thorac Dis. 2013;5:S190-3.

28. Sink EL, Leunig M, Zaltz I, Gilbert JC, Clohisy J, Academic Network for Conservational Hip Outcomes Research Group. Reliability of a complication classification system for orthopaedic surgery. Clin Orthop Relat Res. 2012; 470:2220-6.

29. Mamoulakis C, Efthimiou I, Kazoulis S, Christoulakis I, Sofras F. The modified Clavien classification system: a standardized platform for reporting complications in transurethral resection of the prostate. World J Urol. 2011;29:205-10.
30. Clavien PA, Sanabria JR, Strasberg SM. Proposed classification of complications of surgery with examples of utility in cholecystectomy. Surg. 1992;111:518-26.

Key Words: lung cancer, pulmonary resection, perioperative risk factors, prolonged length of stay, postoperative adverse events 